University of Nebraska - Lincoln

DigitalCommons@University of Nebraska - Lincoln

2010

\title{
The High-Risk Environment of Homeless Young Adults: Consequences for Physical and Sexual Victimization
}

Kimberly A. Tyler

University of Nebraska-Lincoln, kim@ktresearch.net

Morgan R. Beal

University of Nebraska-Lincoln

Follow this and additional works at: https://digitalcommons.unl.edu/sociologyfacpub

Part of the Sociology Commons

Tyler, Kimberly A. and Beal, Morgan R., "The High-Risk Environment of Homeless Young Adults: Consequences for Physical and Sexual Victimization" (2010). Sociology Department, Faculty Publications. 96.

https://digitalcommons.unl.edu/sociologyfacpub/96

This Article is brought to you for free and open access by the Sociology, Department of at DigitalCommons@University of Nebraska - Lincoln. It has been accepted for inclusion in Sociology Department, Faculty Publications by an authorized administrator of DigitalCommons@University of Nebraska - Lincoln. 
Published in Violence and Victims 25:1 (2010), pp. 101-115; doi: 10.1891/0886-6708.25.1.101

Copyright (C) 2010 Springer Publishing Company. Used by permission.

This research was supported by the National Institute of Mental Health (K01MH064897).

\title{
The High-Risk Environment of Homeless Young Adults: Consequences for Physical and Sexual Victimization
}

\author{
Kimberly A. Tyler, PhD \\ Morgan R. Beal, MA \\ University of Nebraska-Lincoln \\ Corresponding author - K. A. Tyler, University of Nebraska-Lincoln, Department of Sociology, \\ 717 Oldfather Hall, Lincoln, NE 68588-0324; e-mail kim@ktresearch.net
}

\begin{abstract}
Little is known about how the social environment of homeless youth contributes to their risk and how it varies for different types of victimization. As such, the current study examines the constructs of victimization theories in order to investigate the potential risk for physical and sexual victimization among homeless young adults. Results revealed that running at an earlier age, running more often, sleeping on the street, panhandling, deviant peers associations, and not having a family member in one's network are associated with more physical victimization. Being female, a sexual minority, having an unkempt physical appearance, panhandling, and having friends who traded sex are associated with more sexual victimization. Overall, we find that the constructs differed in their ability to explain sexual versus physical victimization.
\end{abstract}

Keywords: lifestyle-exposure theory, routine activity theory, youth, risk factors

The prevalence rate for victimization among homeless youth ${ }^{1}$ reveals that between one-third and one-half of these young people have experienced either sexual or physical victimization since being on the street (Baron, 1997; Janus, McCormack, Burgess, \& Hartman, 1987; Kipke, Simon, Montgomery, Unger, \& Iversen, 1997b; Tyler, Hoyt, Whitbeck, \& Cauce, 200 la). Although some studies have documented risk factors for victimization among homeless youth (Baron, 1997; Hoyt, Ryan, \& Cauce, 1999; Terrell, 1997; Tyler et al., 2001a; Tyler, Hoyt, Whitbeck, \& Cauce, 2001b; Whitbeck \& Hoyt, 1999), less is known about how the social context of the street environment relates to victimization because only a handful of studies have utilized victimization theories such as lifestyle-exposure theory (Hindelang, Gottfredson, \& Garofalo, 1978) and routine activity theory (Cohen \& Felson, 1979) and even fewer are able to examine all of the constructs associated with these theories (i.e., proximity, exposure, guardianship, and target congruence).

Even when researchers have applied the four constructs of victimization theories (Hoyt et al., 1999; Tyler, Whitbeck, Hoyt, \& Cauce, 2004; McCarthy \& Hagan, 1992), the way these are measured tends to vary tremendously. Furthermore, few studies have in- 
corporated the physical appearance of homeless youth into the construct of target congruence, which may be of importance. Moreover, studies often consolidate different types of victimization into one category or only examine one form such as sexual victimization. Therefore, little is known about how the social context of the environment is related to different types of victimization. It is possible that the risk factors for physical victimization differ from those of sexual victimization and using lifestyle-exposure and routine activity theories to examine these relationships will help us to better understand the threats that account for the likelihood of specific forms of victimization among this population. This is particularly important for homeless youth who spend much of their time in the street environment engaging in risky survival behaviors (e.g., selling sex and panhandling) that may increase their chances for victimization. Additionally, if we find that certain risk factors are unique to specific forms of victimization, this may have significant implications when targeting this group for intervention. Finally, it is vital to more fully understand this process in order to break the cycle of violence given that those who are victimized once are at risk for subsequent victimization (Baron, 1997). Thus, the purpose of this article is to examine the context of the environment of homeless young adults using the four constructs of victimization theories in order to investigate their usefulness in explaining the potential risk for physical and sexual victimization.

\section{Theoretical Background and Risk Factors for Victimization}

Lifestyle-exposure theory (Hindelang et al., 1978) is associated closely with routine activity theory (Cohen \& Felson, 1979) in that both ignore the sources of criminal motivation and direct attention to how the lifestyles and activities of individuals in their everyday lives are related to differential exposure to dangerous places and people, which creates the potential for crime opportunities and increased victimization. The two major differences between the two approaches lie in the terminology used as well as what they were designed to explain. Routine activity theory was developed to explain the change in crime rates over time whereas lifestyle-exposure theory was designed to account for differential risks for victimization among different social groups (Miethe \& Meier, 1994). Miethe and Meier (1990) combined the features of both theories, including the four central concepts of proximity to crime, exposure to crime, guardianship, and target attractiveness/congruence, into a structural-choice theory of victimization. The concurrence of the four constructs increases the likelihood of being a victim.

Proximity to crime is the physical distance between the areas where potential offenders are found and where potential targets of crime reside (Cohen, Kluegel, \& Land, 1981). It follows that individuals who live in high-crime areas are more likely to have contact with offenders, which increases their risk for victimization. Because many homeless young adults are without a stable residence to which they can return, they spend more time on the street, increasing their proximity to potential offenders and thus their chances for physical and/or sexual victimization. Studies confirm that the more time adolescents spend on the street, the greater the likelihood of engaging in dangerous activities (Janus et al., 1987), which increases the risk for victimization (Hoyt et al., 1999; Tyler et al., 2001a; Whitbeck, Hoyt, \& Yoder, 1999).

Being on the streets increases one's accessibility to crime in addition to increasing the likelihood of contact between oneself and potential offenders (Miethe \& Meier, 1994). Moreover, because personal victimization is associated with the amount of time spent in 
public places, especially at night (Hindelang et al., 1978), homeless young adults are at further risk because much of their time is spent on the streets. Following this, "it was hypothesized that young adults who left home for the first time at an earlier age, those who run from home numerous times, and those who spend more time sleeping on the streets are at greater risk for physical and sexual victimization."

Exposure to crime is characterized by an individual's visibility and accessibility to potential offenders (Cohen et al., 1981). Many homeless youth engage in high-risk behaviors, resulting in an increased risk for victimization (Hagan \& McCarthy, 1997; Whitbeck \& Hoyt, 1999). For example, many homeless young people are exposed through their participation in selling drugs or trading sex in order to make money to obtain the things that they need (Hagan \& McCarthy, 1997) and when they have no other means of obtaining them (Greene, Ennett, \& Ringwalt, 1999). Recruiting potential customers on the street for either strategy results in their high visibility; this increases their risk for physical and sexual victimization. Youth who have friends who trade sex are often pressured and coerced by these people to trade sex (Tyler \& Johnson, 2006). Trading sex or associating with peers who trade sex puts homeless young people in dangerous and vulnerable situations. Other daily survival strategies such as panhandling, which is the practice of asking commuters for money in public areas (Gaetz \& O'Grady, 2002), or hanging out in public places can also increase a young person's chances of physical and/or sexual victimization due to their prolonged exposure. Finally, associating with deviant peers (i.e., those who steal or rob) also exposes homeless youth to potential offenders and has been found to increase their risk for victimization (Tyler et al., 200 la).

Because they lack a stable residence, many homeless young people tend to hang out on the streets and participate in a variety of activities often as a means of survival. As such, the lifestyles and daily routines of these young adults may expose them to potential offenders thereby increasing their chances of becoming victims of physical and/or sexual assault. Based on the above findings, "it was hypothesized that homeless young adults who panhandle, spend time hanging out on the streets, sell sex, and have friends who sell sex are more likely to be sexually victimized." Additionally, "it is expected that homeless young adults who panhandle, hang out on the streets, sell drugs, and who associate with peers who engage in delinquent activities are more likely to be physically victimized."

Capable guardianship is the ability of persons or objects to prevent violations from occurring (Cohen et al., 1981). Guardianship is important because implementing precautions increases the "costs" for the would-be offender, thus decreasing the opportunity for victimization (Miethe \& Meier, 1994). Oftentimes, homeless people have little protection given their current living situation, where they frequently find themselves on the street. Social networks of homeless youth that are comprised of at least one family member, however, have been found to be associated with lower rates of behavioral problems (Milburn et al., 2005) and also act as a buffer against sexual risk taking and substance use among homeless young adults (Tyler, 2008b). As such, having a family member present in one's network may increase the level of guardianship, which is important in preventing victimization from occurring (Cohen et al., 1981). Following this, "it was hypothesized that youth who report having a family member present in their social network are likely to experience lower rates of physical and sexual victimization."

Target congruence refers to persons or objects selected by the offender because they have particular value (Miethe \& Meier, 1994). For example, "femaleness" may be an attribute of the victim that is congruent with the needs and motives of a particular sexual offender (Finkelhor \& Asdigian, 1996); therefore, females are more likely to be victims in 
this particular case. In contrast, "maleness" may be an attribute of the victim that is congruent with the needs of a particular physical offender because males may receive gratification from beating up other men (Finkelhor \& Asdigian, 1996). Therefore, in order to establish dominance or to acquire a reputation as a tough person, males may seek out other men and thus males are more likely to be victims of physical assault.

Age is associated with both physical and sexual assault among youth (Finkelhor \& Asdigian, 1996). Although youth who have been on the streets for longer time periods may have more experience and knowledge about how to remain safe, it may have come at a cost. That is, these older individuals may have learned safety techniques but only after experiencing some episodes of victimization; thus, older youth may be at greater risk due to prolonged exposure.

The literature on homeless youth finds that sexual minorities are more likely to experience victimization (Cochran, Stewart, Ginzler, \& Cauce, 2002; Rew, Whittaker, TaylorSeehafer, \& Smith, 2005; Tyler, 2008a). Gay, lesbian, and bisexual (GLB) youth are also more likely to trade sex compared to their heterosexual peers (Kipke, Montgomery, Simon, Unger, \& Johnson, 1997a; Tyler, 2008a), and trading sex is linked to sexual victimization among homeless youth (Tyler et al., 2004). Additionally, GLBs often suffer from bias-related crimes (Herek, Cogan, \& Gillis, 2002; Willis, 2004); therefore, sexual orientation may be an attribute that is congruent with the needs of offenders.

In terms of physical features, it is possible that males with a kempt appearance may look more attractive to a potential physical offender because they may be seen as having more resources (e.g., money) and thus there is more to gain from a physical attack. In contrast, unattractive individuals have lower self-concept (Agnew, 1984), which may make them more vulnerable to sexual victimization. Because the personal characteristics of homeless young adults may be congruent with the needs and motives of the offender, "it was hypothesized that females, older adolescents, sexual minorities, and those with unkempt physical appearances would be at greater risk for sexual victimization." In addition, "it was hypothesized that males, older adolescents, sexual minorities, and those with kempt physical appearances would be at greater risk for physical victimization." Because very little research has focused specifically on homeless youths' appearance as it relates to both sexual and physical victimization, we consider the hypotheses regarding appearance exploratory.

\section{Methods}

Data are from the Homeless Young Adult Project (HYAP), a pilot study designed to examine the effect of neglect and abuse histories on homeless young adults' mental health and high-risk behaviors. Over a period of approximately 1 year (from April of 2004 through June of 2005), 199 young adults were interviewed in three Midwestern cities. Of this total, 144 were homeless and 55 were currently housed at the time of the interview. The 55 young adults were chosen via peer nominations from their homeless counterparts. Homeless was defined as those currently residing in a shelter, on the street, or those living independently (e.g., with friends) because they had run away, had been pushed out, or had drifted out of their family of origin. Only those who were currently homeless at the time of the interview ( $n=144$ ) were included in the current analyses given that some of the questions (e.g., panhandling) were only asked of homeless respondents. Due to listwise deletion, the final sample used for this research included 127 homeless young adults. 
The interviewers included individuals who have worked on past projects dealing with at-risk individuals, have served for several years in agencies and shelters that support homeless young people, and are very familiar with local street cultures. Additionally, all interviewers completed the Collaborative Institutional Review Board (IRB) Training Initiative course for the protection of human subjects in research.

Interviewers approached shelter residents and located eligible respondents in areas where street people congregate. The sampling protocol included varying the times of the day on both weekdays and weekends that interviewers went to these locations. This protocol was conducted repeatedly over the course of 14 months. This systematic sampling strategy that maximized locating homeless young adults was used because it is well established that it is not possible to randomly sample homeless populations (Wright, Alien, \& Devine, 1995). Interviewers obtained informed consent from young adults prior to participation, told them about the confidentiality of the study, and informed them that their participation was voluntary. The interviews, which were conducted in shelter interview rooms or quiet comers of fast food restaurants or coffee shops, lasted approximately $1 \mathrm{hr}$ and all participants received US \$25 for their involvement. Referrals for shelter, counseling services, and food services were offered to the young adults at the time of the interview. Although field reporters did not formally tally screening rates, they reported that very few young adults refused to participate. The IRB at the University of Nebraska-Lincoln approved this study.

\section{Measures}

\section{Independent Variables}

Proximity measures. Age at first run was a single indicator that measured how old the respondents were when they first ran from home. Due to skew, this variable was collapsed on the younger end such that ages 5 years and younger were combined into one category and ages 6 to 9 years were combined into a second category. The remaining categories (e.g., age 10,11, 12, 13, etc.) were not collapsed given the fairly even distribution within each age group.

Number of times run was a single item indicator that measured the total number of times young people had run away from home. Due to skew, this variable was collapsed into $1=$ ran away once, $2=$ ran away 2 or 3 times, $3=$ ran away 4 or 5 times, $4=$ ran away 6 to 10 times, 5 = ran away 11 to 20 times, and $6=$ ran away more than 20 times.

Street time was a single item indicator that measured the number of nights the respondent spends on the street in an average week. The responses for this item ranged from 0 to 7 nights.

Exposure measures. Panhandling was a single item indicator that asked respondents how often they spent time panhandling. The response categories included $0=$ never, $1=$ some of the time, 2 = half of the time, 3 = most of the time, and $4=$ all of the time. Due to skew, this item was dichotomized such that $0=$ never panhandled and $1=$ panhandled at least some of the time.

Hanging out was a single item indicator that asked respondents how often they spent time hanging out. The response categories included $0=$ never, $1=$ some of the time, $2=$ half of the time, $3=$ most of the time, and $4=$ all of the time.

Selling sex was created using four items concerning prostitution and two items regarding trading sex. First, for prostitution, respondents were asked how often they had engaged in prostitution. Second, interviewers asked respondents how much time they spent 
on the street "turning tricks." Third, in an open-ended question, some youth reported having engaged in prostitution when they had few other options. Finally, another openended question asked youth what kind of work they did, and some youth reported that prostitution was their source of employment. These four prostitution items were combined into a single variable $(0=$ never prostituted, $1=$ have prostituted $)$. The first trading sex item asked respondents if they had ever traded sex in return for money, a place to stay, or drugs. Additionally, an open-ended question asked youth what kinds of things they had done to get by on the streets. Those who indicated that they had traded sex were included in this count. These two trading sex items were combined into a single variable regarding whether they had ever traded sex $(0=n o$ and $1=$ yes $)$. Finally, a composite ever sold sex variable was created using the prostitution and trading sex variables where $0=$ never sold sex and $1=$ sold sex at least once.

Friends traded sex was a single item that asked young people if any of their friends had ever traded sex for food, money, and/or shelter. Responses included $0=n o$ and $1=y e s$.

Selling drugs was a single item that asked respondents how often they had sold drugs since leaving home. Response categories ranged from $0=$ never to $3=$ many times $(5$ or more).

Deviant peers was measured by asking respondents if any of their close friends had ever engaged in a series of seven delinquent activities such as stealing, robbing, fighting, or selling drugs (adapted from Whitbeck \& Simons, 1990). These seven dichotomous items were summed into an index with higher scores indicating greater involvement in deviant behaviors by the respondent's close friends.

Guardianship measure. The family member variable was assessed by asking youth to give the initials of those who they currently spend the most time with and then were asked what their relationship was to this person in their network (e.g., friend, family member, or boyfriend/girlfriend). Because research has shown that having a family member in the network can buffer against high-risk behaviors (Ennett, Bailey, \& Federman, 1999), this variable was coded as $0=$ no family members present and $1=$ at least 1 family member present in their network.

Target congruence measures. Gender was coded $0=$ male and $1=$ female. Age was the age of the respondent at the time of the interview, and sexual orientation was coded $0=G L B$ and 1 = heterosexual.

Appearance of the youth was a single item in which interviewers were asked to rate the appearance of the young adult in terms of their facial and body features. In terms of grooming, the interviewer was asked to rate the youth's grooming, dress, and cleanliness. Response categories for both items ranged from $1=$ very unattractive to $5=$ very attractive. Interviewers rated the youth on these items after the interview and before examining the completed questionnaire.

Dependent Variables. Physical victimization was measured with six items that asked respondents, for example, how many times they had been beaten up, robbed, or threatened with a weapon. The items were summed with a higher score indicating greater physical victimization. Cronbach's alpha was .77. All of the independent variables described above were used to predict physical victimization with the exception of selling sex and friends trading sex.

Sexual victimization consisted of four items that asked respondents, for example, how many times they had been touched sexually when they did not want to be and sexually assaulted and/or raped. Each of the individual items were dichotomized due to skew and then summed with a higher score indicating greater sexual victimization. Cronbach's 
alpha was .83. All of the independent variables described above were used to predict sexual victimization with the exception of selling drugs and deviant peers.

\section{Results}

\section{Sample Characteristics}

The sample included 36 females (28\%) and 91 males (72\%). Ages ranged from 19 to 26 years with a mean of 21.5 years. Seventeen percent of the sample identified as GLB. One half of the sample (50\%) had received at least a high school diploma, and the majority of respondents were white $(78 \%)$. The average age at which youth ran from home was 14.5 years, and most young people ran 2 or 3 times. Twenty percent of youth spent 2 or 3 nights on the street, while $11 \%$ reported spending 7 nights a week on the street. Over one-quarter of the sample $(27 \%)$ had panhandled at least once, and $50 \%$ reported spending most or all of their time hanging out. Sixteen percent of youth reported selling sex, and $32 \%$ reported having friends who have done so. Approximately one-third of individuals reported having close friends who engaged in all seven deviant behaviors (e.g., stealing, robbing), whereas $27 \%$ of respondents said they themselves sold drugs many times. Only $11 \%$ of youth reported having a family member in their social network. The majority of respondents $(94 \%)$ had experienced some type of physical victimization since being on the street, and $32 \%$ had been sexually victimized at least once. Interviewers rated the majority of youth (59\%) as attractive or very attractive, and $62 \%$ of youth were seen as attractive or very attractive in terms of their grooming, dress, and cleanliness.

The bivariate correlations, means, and standard deviations for all study variables are presented in Table 1. Results revealed that sexual victimization is significantly associated with panhandling $(r=.38)$, ever selling sex $(r=.41)$, friends ever trading sex $(r=.33)$, gen$\operatorname{der}(r=.40)$, and sexual orientation $(r=-.44)$. Physical victimization is significantly associated with age at first run $(r=-.29)$, total number of times run $(r=.30)$, street time $(r=.30)$, panhandling $(r=.37)$, deviant peers $(r=.37)$, and respondent selling drugs $(r=.35)$.

Tables 2 and 3 show the ordinary least squares (OLS) regression models for correlates of sexual and physical victimization, respectively. The variables were entered in four separate blocks so we could see the individual effect of each of the four central constructs used in victimization theories (i.e., proximity, exposure, guardianship, and target congruence). Model 1 (Table 2 ) revealed that none of the proximity variables were associated with sexual victimization. In Model 2 the exposure items were added, revealing that youth who have panhandled at least once $(\beta=.28)$, who have ever sold sex $(\beta=.28)$, and who report having friends who trade sex $(\beta=.19)$ are likely to experience more sexual victimization. None of the proximity items were significant. Model 2 explained $25 \%$ of the variance in sexual victimization with the addition of the exposure items. In Model 3, the addition of the guardianship variable was not significant. Similar to Model 2, none of the proximity items reached significance, while panhandling, selling sex, and friends trading sex all remained significant correlates. In Model 4, the addition of the target congruence variables significantly improved the fit of the model from $26 \%$ in Model 3 to $43 \%$ in Model 4. Females $(\beta=.34)$, GLB's $(\beta=-.25)$ and those who had a less pleasing physical appearance $(\beta=-.19)$ were more likely to have experienced greater sexual victimization. The guardianship variable remained nonsignificant. Panhandling and friends trading sex remained positively associated with sexual victimization. 


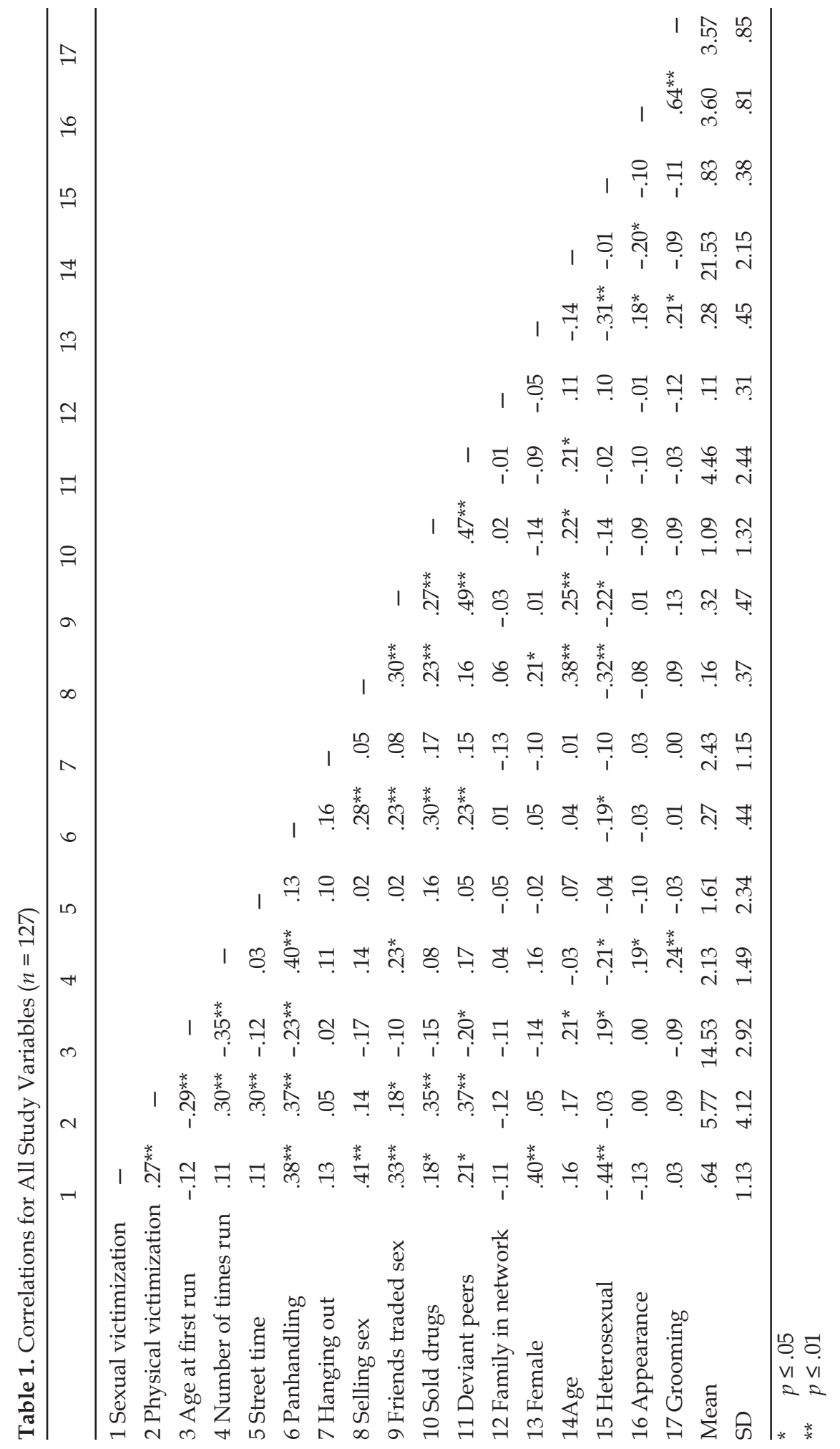


Table 2. OLS Regression Models for Correlates of Sexual Victimization

\begin{tabular}{|c|c|c|c|c|c|c|c|c|}
\hline & \multicolumn{2}{|c|}{ Model 1} & \multicolumn{2}{|c|}{ Model 2} & \multicolumn{2}{|c|}{ Model 3} & \multicolumn{2}{|c|}{ Model 4} \\
\hline & $\beta$ & $S E$ & $\beta$ & $S E$ & $\beta$ & $S E$ & $\beta$ & $S E$ \\
\hline \multicolumn{9}{|l|}{ Proximity } \\
\hline Age at first run & -.09 & .04 & -.03 & .03 & -.04 & .03 & .00 & .03 \\
\hline Number of times run & .08 & .07 & -.10 & .07 & -.10 & .07 & -.15 & .06 \\
\hline Street time & .09 & .04 & .05 & .04 & .05 & .04 & .03 & .03 \\
\hline \multicolumn{9}{|l|}{ Exposure } \\
\hline Panhandling & & & $.28^{\star *}$ & .23 & $.29^{* *}$ & .23 & $.29 * *$ & .20 \\
\hline Hanging out & & & .06 & .08 & .05 & .08 & .09 & .07 \\
\hline Respondent selling se & & & $.28^{* *}$ & .26 & $.29 * *$ & .26 & .10 & \\
\hline \multicolumn{9}{|l|}{.26} \\
\hline Friends trading sex & & & $.19^{*}$ & .20 & $.18^{*}$ & .20 & $.15^{*}$ & .18 \\
\hline \multicolumn{9}{|l|}{ Guardianship } \\
\hline Family member in ne & twork & & & & -.11 & .28 & -.06 & .25 \\
\hline \multicolumn{9}{|l|}{ Target Congruence } \\
\hline Female & & & & & & & $.34^{* *}$ & .19 \\
\hline Age & & & & & & & .09 & .04 \\
\hline Heterosexual & & & & & & & $-.25^{* *}$ & .23 \\
\hline Respondent's appear & ance & & & & & & $-.19^{*}$ & .13 \\
\hline Respondent's groomi & & & & & & & .08 & .12 \\
\hline Adjusted $R^{2}$ & .01 & & .25 & & .26 & & .43 & \\
\hline
\end{tabular}

* $\quad p \leq .05$ level of significance (two-tailed)

** $\quad p \leq .01$ level of significance (two-tailed)

Model 1 (Table 3) revealed the importance of the proximity variables for physical victimization: those who ran away at an earlier age $(\beta=-.18)$, those who ran more often ( $\beta$ $=.25)$, and those who spent more time sleeping on the street $(\beta=.28)$ were significantly more likely to have experienced greater physical victimization. These variables alone explained $20 \%$ of the variance in the dependent variable. In Model 2, the exposure items of panhandling $(\beta=.17)$, selling drugs $(\beta=.16+)$, and more deviant peers $(\mathrm{P}=.22)$ were all associated with a greater likelihood of physical victimization. Number of times run and street time remained positively associated with being a victim of physical assault. Model 2 explained 32\% of the variance. Although the guardianship variable in Model 3 was significant based on a one-tail test consistent with our hypothesis $(\beta=-.14+)$, this variable did not significantly improve the fit of the model. However, it does reveal that those who do not have a family member present in their network are more likely to experience greater physical victimization. The same proximity and exposure items that were significant in Model 2 remained significant in Model 3. Finally in Model 4, the addition of the target congruence items did not explain any additional variance, and none of these variables reached statistical significance. 
Table 3. OLS Regression for Correlates of Physical Victimization

\begin{tabular}{|c|c|c|c|c|c|c|c|c|}
\hline & \multicolumn{2}{|c|}{ Model 1} & \multicolumn{2}{|c|}{ Model 2} & \multicolumn{2}{|c|}{ Model 3} & \multicolumn{2}{|c|}{ Model 4} \\
\hline & $\beta$ & $S E$ & $\beta$ & $S E$ & $\beta$ & $S E$ & $\beta$ & $S E$ \\
\hline \multicolumn{9}{|l|}{ Proximity } \\
\hline Age at first run & $-.18^{*}$ & .12 & -.11 & .11 & -.12 & .11 & $-.16+$ & .12 \\
\hline Number of times run & $.25^{* *}$ & .24 & $.16+$ & .24 & $.17^{*}$ & .23 & $.16+$ & .25 \\
\hline Street time & $.28^{* *}$ & .14 & $.23^{* *}$ & .14 & $.23^{* *}$ & .13 & $.22^{* *}$ & .14 \\
\hline \multicolumn{9}{|l|}{ Exposure } \\
\hline Panhandling & & & $.17^{*}$ & .80 & $.17^{*}$ & .79 & $.17^{*}$ & .81 \\
\hline Hanging out & & & -.06 & .27 & -.08 & .27 & -.07 & .27 \\
\hline Sold drugs & & & $.16+$ & .27 & $.16+$ & .27 & .14 & .28 \\
\hline Deviant peers & & & $.22 * *$ & .15 & $.22 * *$ & .15 & $.22^{*}$ & .15 \\
\hline \multicolumn{9}{|l|}{ Guardianship } \\
\hline Family member in net & vork & & & & $-.14+$ & .99 & $-.16^{*}$ & 1.03 \\
\hline \multicolumn{9}{|l|}{ Target Congruence } \\
\hline Female & & & & & & & .06 & .74 \\
\hline Age & & & & & & & .12 & .16 \\
\hline Heterosexual & & & & & & & .10 & .87 \\
\hline Respondent's appeara & & & & & & & .03 & .52 \\
\hline Respondent's groomin & & & & & & & -.01 & .47 \\
\hline Adjusted $R^{2}$ & .20 & & .32 & & .33 & & .32 & \\
\hline
\end{tabular}

\section{Discussion}

The purpose of this article was to examine which risk factors are associated with specific forms of victimization and investigate whether the constructs differ in their ability to explain sexual versus physical victimization. This is important given that very little research in this area has examined all four constructs and fewer studies have looked at different types of victimization. Our results reveal that indeed different constructs are important. That is, target congruence and exposure are helpful for explaining sexual victimization, whereas proximity and exposure are useful for explaining physical victimization.

\section{Sexual Victimization}

Exposure to crime is useful for explaining sexual victimization in the current study. Specifically, youth who panhandle and those who have friends who trade sex experience more sexual victimization, which is consistent with our hypotheses. It is likely that engaging in 
survival strategies such as panhandling exposes these youth to a wide variety of people. If homeless youth panhandle on a regular basis, they are easily visible and accessible to potential offenders, thereby increasing their chances of being a victim of sexual assault. In addition, homeless youth who have friends who trade sex are often pressured and coerced by these people to engage in this behavior (Tyler \& Johnson, 2006). Research also finds that having friends who trade sex is indirectly linked to sexual victimization via youth themselves trading sex (Tyler, Hoyt, \& Whitbeck, 2000). Associating with peers who trade sex likely puts homeless young people in dangerous and vulnerable situations where they are highly visible and have little or no protection from violent customers and others who may try to exploit them. Although selling sex was not significant in our final model, it was significant in the previous two models prior to adding in the target congruence variables.

Target congruence is an important construct for explaining sexual victimization among our sample. As hypothesized, females and GLBs experience higher levels of sexual victimization compared to males and heterosexual youth. Consistent with other studies (Finkelhor \& Asdigian, 1996), femaleness is likely an attribute that is congruent with the needs and motives of a particular sexual offender regardless of anything that the young women do. In addition, one's sexual orientation is likely an attribute that is congruent with the needs of some sexual offenders; this is supported by the literature that finds that GLB youth are often the targets of bias-related crimes (Herek et al., 2002; Willis, 2004).

We also find that youth with unattractive physical appearances experienced greater sexual victimization, which is consistent with our hypothesis. One possible explanation for why these youth are more likely to be targeted is because perpetrators may view them as having few resources (e.g., lack of friends). In addition, these youth may be less likely to seek help from law enforcement; therefore, the perpetrator might conclude that by victimizing individuals with an unkempt appearance, they are less likely to suffer negative outcomes. As such, a less pleasing physical appearance is congruent with the needs of some sexual offenders. Although research in this area is limited, the work of Agnew (1984) provides some general support for our explanation. Agnew hypothesized that unattractive individuals are more likely to be viewed as delinquent and therefore conventional peers are less likely to associate with them (Agnew, 1984). If unattractive individuals have fewer friends, this suggests that unkempt homeless youth may be more likely to be out on the street by themselves, which may increase their risk for victimization. Overall, the two constructs of exposure and target congruence explained significant variance in our outcome measure of sexual victimization.

\section{Physical Victimization}

Proximity to crime is important for explaining physical victimization in the current study. Specifically, we find that running from home at an earlier age, running away numerous times, and spending more time sleeping on the streets are all associated with being a victim of physical assault, which is consistent with our hypotheses. It is likely that homeless youth who spend a greater amount of time on the street and who sleep in public places are more likely to have contact with offenders, which increases their risk for physical victimization, which is consistent with previous research (Hagan \& McCarthy, 1997; Hoyt et al., 1999).

Exposure to crime and guardianship are also important constructs for understanding physical victimization among homeless youth. Specifically we find that those who panhandle, associate with more deviant peers, and who do not have a family member present in their network experience higher rates of physical victimization, which is consistent with our 
expectations. Panhandling is a survival strategy that results in homeless youth being highly visibility and therefore makes them more accessible to potential offenders thereby increasing their chances of being a victim of physical assault. In addition, associating with close friends who engage in delinquent activities (i.e., deviant peers) is also a risk factor for victimization (Tyler et al., 2001a). Homeless youth who have close friends who steal, rob, and beat people up are likely to be highly visible and accessible to potential offenders, even if they are not engaging in these behaviors at the time. Merely associating with these close friends may be enough to make them future targets for physical aggression.

In terms of guardianship, we find that spending a lot of time with a family member buffers against physical victimization. This buffering effect is consistent with other research which finds that family members serve a protective role by discouraging risky practices (Ennett et al., 1999). If youth are not engaging in risky behaviors, they may be less likely to come into contact with potential offenders and thus are less likely to be victimized. In addition, spending time with a family member implies that youth have access to more traditional forms of instrumental and emotional support. In contrast, those who spend most of their time with street peers may only be offered support in the form of deviant survival strategies (Hagan \& McCarthy, 1997). Having close ties to a family member may also mean having a safe place to sleep, which removes youth from the street environment and thus lowers their risk for physical victimization.

Some limitations should be noted. First, all data are based on self-reports. Despite this, participants were informed that their responses would be confidential and the interviewers were already known and trusted by many of the young people so it is less likely that the respondents would be motivated to bias their responses. Another limitation is the retrospective nature of many of the measures, which may have resulted in some over- or underreporting. Third, this study was cross-sectional; therefore, we cannot make inferences about causality. Finally, we were unable to examine inter-rater reliability for the measures of appearance and grooming.

Despite these limitations, this article has numerous strengths and contributes to our understanding of physical and sexual victimization among homeless young adults within the street context. According to victimization theories, youth who engage in subsistence strategies are easily visible which makes them more accessible to potential offenders. Additionally, those who spend more time on the street have less physical distance between themselves and potential threats and as such, are at higher risk for physical victimization: the current findings lend support to both of these constructs. In addition, although we find some support for the construct of guardianship within our physical victimization model, it did not explain additional variance. Finally, our results are supportive of the target congruence construct in that females, GLBs, and those with an unkempt appearance are more likely to become victims because these are characteristics that are congruent with the needs of sexual offenders. Overall, being exposed through participation in survival strategies increases one's risk for both sexual and physical victimization among homeless youth.

In sum, although victimization theories are very helpful for explaining our results with homeless youth, we find that the usefulness of the individual constructs vary by the type of victimization. That is, proximity and exposure are most important for explaining physical victimization whereas exposure and target congruence are relevant for explaining sexual victimization. Regardless of victimization type, it appears that exposure through subsistence strategies is an extremely important construct. Because of the lack of research within this population, we have little with which to compare our results. Future studies should build upon our findings and examine how the four constructs of victimization theories, es- 
pecially target congruence, are related to different types of victimization among this population. Although women and sexual minorities are at greater risk for sexual victimization, we did not find this link for physical victimization. Replication is needed in order to determine whether or not these findings are unique to our sample. If women and sexual minorities are consistently at greater risk, this has implications for prevention and intervention with these two social groups. This is also an important area for future research given the large number of sexual minorities who run away from home (Cochran et al., 2002).

At the policy level, our results have practical implications for service providers who work with homeless individuals. Foremost is the fact that many of these young people have experienced physical and/or sexual victimization since being on their own. Related to this is the fact that numerous youth engage in risky behaviors as a means of survival (e.g., panhandle, sell drugs, trade sex), which also increases their risk for victimization. Training programs that work toward building skills in the area of self-esteem and self-efficacy may enhance the overall well-being of these youth and thus lower their risk for future victimization. In addition, if youth had other alternatives to making money, they may be less inclined to trade sex or sell drugs. Thus, increased funding for educational and job training programs that emphasize skills such as constructing a resume, interviewing skills, and job searching techniques would allow youth to acquire and maintain stable employment, reducing the likelihood of future victimization. Additionally, some youth who lack alternatives are forced to sleep on the street, which puts them at high risk for victimization. Increased funding for drop-in centers, counselors, shelters, and especially street-based outreach workers who can locate these youth and provide them with necessary services is also needed. Because many of these youth have run from abusive homes, have experienced revictimization on the street, and have limited employment skills, programs need to be able to address a multitude of issues to be successful. In fact, research finds that the most successful interventions are those that address the broader matrix of problems that these young people face (Cauce et al., 1998). With these practical policy interventions, youth will be given opportunities and realistic expectations, which will aid them in being successful at leaving the street environment and ending the cycle of victimization.

\section{Note}

1. The term "youth" is used interchangeably with "young adults" throughout the article.

\section{References}

Agnew, R. (1984). Appearance and delinquency. Criminology, 22, 421-440.

Baron, S. W. (1997). Risky lifestyles and the link between offending and victimization. Studies of Crime and Crime Prevention, 6, 53-71.

Cauce, A. M., Paradise, M., Embry, L., Morgan, C. J., Lohr, Y., Theofelis, J., et al. (1998). Homeless youth in Seattle: Youth characteristics, mental health needs, and intensive case management. In K. Kutash, A. Duchnowski, \& M. Epstein (Eds.), Community-based programming for children with serious emotional disturbances: Research and evaluation (pp. 611-632). Baltimore Brookes Publishing.

Cochran, B. N., Stewart, A. J., Ginzler, J. A., \& Cauce, A. M. (2002). Challenges faced by homeless sexual minorities: Comparison of gay, lesbian, bisexual, and transgender homeless adolescents with their heterosexual counterparts. American Journal of Public Health, 92, 773-777. 
Cohen, L. E., \& Felson, M. (1979). Social change and crime rate trends: A routine activity approach. American Sociological Review, 44, 588-608.

Cohen, L. E., Kluegel, J. R., \& Land, K. C. (1981). Social inequality and predatory criminal victimization: An exposition and test of a formal theory. American Sociological Review, 46, 505-524.

Ennett, S. T., Bailey, S. L., \& Federman, E. B. (1999). Social network characteristics associated with risky behaviors among homeless and runaway youth. Journal of Health and Social Behavior, 40, 63-78.

Finkelhor, D., \& Asdigian, N. L. (1996). Risk factors for youth victimization: Beyond a lifestyle/routine activities theory approach. Violence and Victims, 11, 3-19.

Gaetz, S., \& O'Grady, B. (2002). Making money: Exploring the economy of young homeless workers. Work, Employment and Society, 16, 433-456.

Greene, J. M., Ennett, S. T., \& Ringwalt, C. L. (1999). Prevalence and correlates of survival sex among runaway and homeless youth. American Journal of Public Health, 89, 1406-1409.

Hagan, J., \& McCarthy, B. (1997). Mean streets: Youth crime and homelessness. New York: Cambridge University Press.

Herek, G. M., Cogan, J. C., \& Gillis, J. R. (2002). Victim experiences in hate crimes based on sexual orientation. Journal of Social Issues, 58, 319-339.

Hindelang, M., Gottfredson, M., \& Garofalo, J. (1978). Victims of personal crime: An empirical foundation for a theory of victimization. Cambridge: Ballinger.

Hoyt, D. R., Ryan, K. D., \& Cauce, A. M. (1999). Personal victimization in a high-risk environment: Evaluating the relative effects of exposure, attractiveness and guardianship. Journal of Research in Crime and Delinquency, 36, 371-392.

Janus, M. D., McCormack, A., Burgess, W. A., \& Hartman, C. (1987). Adolescent runaways: Causes and consequences. Lexington, MA: Lexington Press.

Kipke, M. D., Montgomery, S. B., Simon, T. R., Unger, J. B., \& Johnson, C. J. (1997a). Homeless youth: Drug use patterns and HIV risk profiles according to peer group affiliation. AIDS and Behavior, 1, 247-259.

Kipke, M. D., Simon, T., Montgomery, S. B., Unger, J. B., \& Iversen, E. R (1997b). Homeless youth and their exposure to involvement in violence while living on the streets. Journal of Adolescent Health, 20, 360-367.

McCarthy, B., \& Hagan, J. (1992). Surviving on the street: The experiences of homeless youth. Journal of Adolescent Research, 7, 412^430.

Miethe, T. D., \& Meier, R. F. (1990). Opportunity, choice, and criminal victimization: A test of a theoretical model. Journal of Research in Crime and Delinquency, 27, 243-266.

Miethe, T. D., \& Meier, R. F. (1994). Crime and its social context: Toward an integrated theory of offenders, victims, and situations. Albany, NY: State University of New York Press.

Milburn, N. G., Rotheram-Borus, M. J., Batterham, P., Brumback, B., Rosenthal, D., \& Mallett, S. (2005). Predictors of close family relationships over one year among homeless young people. Journal of Adolescence, 28, 263-275.

Rew, L., Whittaker, T. A., Taylor-Seehafer, M. A., \& Smith, L. R. (2005). Sexual health risks and protective resources in gay, lesbian, and bisexual, and heterosexual homeless youth. Journal for Specialists in Pediatric Nursing, 10, 11-19.

Terrell, N. E. (1997). Street life: Aggravated and sexual assaults among homeless and runaway adolescents. Youth \& Society, 28, 267-290.

Tyler, K. A. (2008a). A comparison of risk factors for sexual victimization among gay, lesbian, bisexual, and heterosexual homeless young adults. Violence and Victims, 23, 586-602.

Tyler, K. A. (2008b). Social network characteristics and risky sexual and drug related behaviors among homeless young adults. Social Science Research, 37, 673-685.

Tyler, K. A., Hoyt, D. R., \& Whitbeck, L. B. (2000). The effects of early sexual abuse on later sexual victimization among female homeless and runaway youth. Journal of Interpersonal Violence, $15,235-250$. 
Tyler, K. A., Hoyt, D. R., Whitbeck, L. B., \& Cauce, A. M. (2001a). The impact of childhood sexual abuse on later sexual victimization among runaway youth. Journal of Research on Adolescence, 11, 151-176.

Tyler, K. A., Hoyt, D. R., Whitbeck, L. B., \& Cauce, A. M. (2001b). The effects of a high-risk environment on the sexual victimization of homeless and runaway youth. Violence and Victims, 16, 441-455.

Tyler, K. A., \& Johnson, K. A. (2006). Trading sex: Voluntary or coerced? The experiences of homeless youth. Journal of Sex Research, 43, 208-216.

Tyler, K. A., Whitbeck, L. B., Hoyt, D. R., \& Cauce, A. M. (2004). Risk factors for sexual victimization among male and female homeless and runaway youth. Journal of Interpersonal Violence, $79,503-520$.

Whitbeck, L. B., \& Hoyt, D. R. (1999). Nowhere to grow: Homeless and runaway adolescents and their families. New York: Aldine de Gruyter.

Whitbeck, L. B., Hoyt, D. R., \& Yoder, K. A. (1999). A risk-amplification model of victimization and depressive symptoms among runaway and homeless adolescents. American Journal of Community Psychology, 27, 273-296.

Whitbeck, L. B., \& Simons, R. L. (1990). Life on the streets: The victimization of runaway and homeless adolescents. Youth \& Society, 22, 108-125.

Willis, D. G. (2004). Hate crimes against gay males: An overview. Issues in Mental Health Nursing, $25,115-132$.

Wright, J. D., Alien, T. L., \& Devine, J. A. (1995). Tracking non-traditional populations in longitudinal studies. Evaluation and Program Planning, 18, 267-277. 